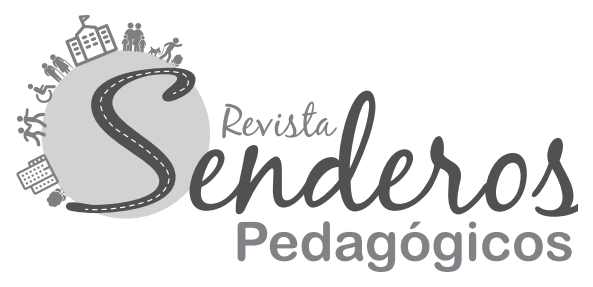

\title{
Representaciones sociales sobre la educación religiosa en adolescentes con identidad religiosa minoritaria ${ }^{1}$
}

\author{
Social representations about religious education in adolescents with \\ minority religious identity
}

\section{Autora: \\ Bibiana Marcela Castaño Hernández}

Recibido: 31/05/2020

Aprobado: 05/10/2020
1. Este artículo surge como reflexión derivada de la investigación: Representaciones sociales sobre la educación religiosa en adolescentes con identidad religiosa minoritaria (2018); tesis de la Maestría en Educación del Tecnológico de Antioquia, Institución Universitaria.

2. Licenciada en Educación Básica con énfasis en Humanidades y Lengua Castellana, Magíster en Educación del Tecnológico de Antioquia, Institución Universitaria. Docente de cátedra del Instituto Tecnológico Metropolitano (ITM).bibimar2003@hotmail.com

\section{Resumen:}

El estudio analiza la voz de adolescentes pertenecientes a diferentes minorías religiosas, sus experiencias y Representaciones Sociales (RS) frente a la Educación Religiosa Escolar (ERE) (creencias, imaginarios ideologías, percepciones, opiniones); a partir de la posibilidad de expresión, escucha y reconocimiento de su identidad religiosa o civil en contextos educativos (públicos y privados), los entornos de aula de distintas instituciones educativas de Medellín, y las limitaciones para comprender y afrontar la identidad y diversidad que convergen en el aula de clase en términos de la opción religiosa. En razón de ello, se utilizó una metodología cualitativa interpretativa, que desde el análisis de caso grupal (4 casos) promovió la interpretación de la información, el contenidoylos sentidos que los participantes en el estudio dieron a las interacciones, experiencias y concepciones compartidas frente a la enseñanza, el aprendizaje, la formación y la evaluación en el área de religión. 
Palabras clave: identidad, Representaciones Sociales (RS), Educación Religiosa Escolar (ERE), minorías religiosas, diversidad.

\begin{abstract}
:
The study analyzes the voice of adolescents belonging to different religious minorities, their experiences and Social Representations (SR) against the Religious School Education (ERE for its abbreviation in Spanish), (beliefs, imaginaries, ideologies, perceptions, opinions); from the possibility of expression, listening and recognition of their religious or civil identity in educational contexts (public and private), the classroom environments of different educational institutions in Medellín, and the limitations to
\end{abstract}

understand and confront the identity and diversity that converge in the classroom in terms of the religious option. Therefore, an interpretative qualitative methodology was used, which from the group case analysis (4 cases) promoted the interpretation of the information, content, and meanings that the participants in the study gave to the shared interactions, experiences and conceptions regarding teaching, learning, training, and evaluation in the subject of religion.

Keywords: identity, Social Representations (SR), School Religious Education (ERE for its abbreviation in Spanish), religious minorities, diversity.

\section{Introducción}

A lo largo de la historia de la humanidad se puede ver cómo la falta de reconocimiento de la identidad religiosa, sea por modos particulares de ser, ver, representar, entender la vida, relacionarse y vivir en sociedad, ha acabado en guerras, exterminios, odios, exclusiones, discriminaciones, represiones. Ante este hecho histórico y sin contexto determinado surgen interrogantes, tales como: ¿cuál ha sido y es el papel de la educación frente a la identidad religiosa?, ¿cómo ha promovido el sistema educativo el reconocimiento de la identidad y diversidad religiosa en el proceso formativo de las diferentes generaciones?

En el contexto colombiano, la ERE pertenece a un pensum compartido entre las escuelas públicas y privadas; es considerada área fundamental y obligatoria para los niveles de educación básica secundaria y media en la Ley General de Educación (Congreso de la República, 1994, art. 24); por lo tanto, está regulada por los estándares curriculares (MEN, 2012), y los contenidos y competencias del área (MEN, 2014). Estas orientaciones son emitidas y reguladas por el Ministerio de Educación Nacional (MEN) y la Conferencia Episcopal Colombiana: “[e]n esta práctica la educación religiosa se desarrolla con estándares, tiempo, docentes, textos y materiales específicos. Se orienta a propiciar el conocimiento religioso con fines formativos, propiciando también la relación con las demás áreas del conocimiento" (Conferencia Episcopal de Colombia, 2009, p. 9). Perspectiva a partir de la cual la 
ERE llega a ser excluyente, porque solo considera contenidos y prácticas de enseñanza católica, obviando la pluralidad y diversidad religiosa de los estudiantes pertenecientes a minorías religiosas.

De acuerdo con la Ley 115 de 1994, la clase de religión "es opcional”3 para los estudiantes pertenecientes a minorías, los padres de familia pueden acceder al derecho constitucional para que sus hijos no reciban esta asignatura; sin embargo, ni estudiantes ni padres conocen este derecho y consideran la clase como una obligación, así como las actividades y rituales católicos que se celebran en establecimientos educativos y de los que deben participar, lo cual: “[...] representa una forma de discriminación para los estudiantes ateos y para los miembros de minorías religiosas diferentes a la católica, quienes participan en este tipo de actividades para no exponerse a sanciones simbólicas ejercidas por sus compañeros o profesores” (Castiblanco y Gómez, 2008, p. 133).

Además, el hacer uso del derecho de no recibir educación religiosa representa un problema serio de orden educativo; de acuerdo con lo que contempla el MEN en los lineamientos curriculares para la enseñanza de la educación religiosa se establece que:

Los alumnos menores de edad cuyos padres hacen uso del derecho de no recibir educación religiosa y los alumnos mayores de edad que hacen uso de ese mismo derecho, plantean un problema serio de orden educativo que no se reduce a problemas disciplinares. Se trata de que estos alumnos se privan del acceso a un componente de la cultura altamente formativo de la personalidad e integrador a la plenitud de la misma (cultura). ¿Qué actividades curriculares se deberán desarrollar con estos alumnos que seriamente contribuyan al desarrollo integral de la personalidad y al conocimiento pleno de su cultura de pertenencia y de las demás culturas? La alternativa al área de educación religiosa debe contemplar la misma seriedad académica y la misma seriedad pedagógica y metodológica para que no queden con un vacío formativo y cultural que afecte gravemente el desarrollo integral humano de estos alumnos. El PEI debe considerar seriamente en sus contenidos esta situación (MEN (s.f.), Oficina Asesora Jurídica).

De acuerdo con lo anterior, queda claro que, en las instituciones educativas del Estado, el que las minorías hagan uso del derecho a no recibir clase de religión, constituye un problema que puede poner en riesgo la homogenización cultural. Además, según lo planteado es la ERE a partir de la cual se logra el desarrollo

3. Resulta contradictorio decir que es opcional cuando se evalúa y se pierde como cualquier otra asignatura, no se dan diferentes opciones y se considera un área fundamental y obligatoria. 
integral de la personalidad; lo que muestra que hay exclusión en la forma como se está abordando y pensando la enseñanza religiosa, porque no se considera opciones que involucren la identidad religiosa y/o civil de todos los educandos y, por ende, múltiples alternativas.

En tal sentido, los estudiantes adscritos a minorías, que son portadores de ideologías y creencias (formas de ver y entender el mundo que consideran verdaderas) diferentes a las sugeridas por el sistema educativo, aun así, deben aprender y ser evaluados desde una ideología religiosa de la cual difieren. Quedaría en cuestión el derecho a la libertad religiosa, la formación ciudadana, el no reconocimiento de la identidad religiosa (Congreso de la República de Colombia, 1991, CPNC, art. 19). También la pregunta de si esta situación indica que existe riesgo de vulnerabilidad sobre el derecho a la libertad religiosa de la población con identidad religiosa minoritaria.

En la actualidad, la religión católica persiste como la más reconocida e influyente en la sociedad y el Estado, sobreviven prácticas como altares a imágenes católicas, celebraciones y ceremonias religiosas en colegios y escuelas públicas, argumentos que dejan en cuestión la libertad de cultos, el reconocimiento de otras culturas, de otras formas de pensamiento, de otras identidades e incluso la laicidad del Estado Colombiano, entendiendo que: “[...] un Estado laico no es antirreligioso o anticlerical, sino un estado que respeta a todas las formas religiosas, sin aceptar ninguna como oficial o privilegiada, pero que al mismo tiempo mantiene una relación amistosa y tolerante con todas ellas" (Arboleda Guerrra, 2006, p. 174).

En suma, la religión en Colombia siempre ha tenido un papel preponderante como recurso cultural, político y social. Al día de hoy, y pese a la proliferación de nuevas formas religiosas, que dieron paso a procesos de reconocimiento de la pluralización religiosa y cultural en la Constitución Política de 1991, la iglesia católica conserva vigente su carácter privilegiado ante el Estado Colombiano, en relación con las demás denominaciones religiosas:

[...] todos los centros de educación primaria y secundaria, incluso las escuelas y colegios del Estado, están obligados a ofrecer un curso de religión de tipo confesional católico, aunque los estudiantes no se encuentran obligados a seguirlo [...] En el desarrollo del derecho que tienen las familias católicas de que sus hijos reciban educación religiosa acorde con su fe, los planes educativos, en los niveles de primaria y secundaria, incluirán en los establecimientos oficiales enseñanza y formación religiosa según el Magisterio de la Iglesia. Para la efectividad de este derecho, corresponde a la competente autoridad eclesiástica suministrar los programas, aprobar los textos 
de enseñanza religiosa y comprobar cómo se imparte dicha enseñanza (Beltrán, 2013, p. 127) ${ }^{4}$.

Según lo anterior, se deduce que el derecho de las minorías, no solo a la libertad religiosa, o al reconocimiento de su identidad, sino incluso a la igualdad, es vulnerado desde la legalidad, ya que el Estado y, por ende, el sistema educativo confieren privilegios solo a la parte de la población con la cual tienen afinidad religiosa, para el caso, la católica. Pero, ¿no se promulga Colombia como un Estado Laico?

La Constitución Política de 1991 establece que Colombia es un país laico; promulga el reconocimiento de la libertad religiosa y la igualdad entre todas las confesiones religiosas. "El Estado laico determina que las leyes civiles valen igual para todos, sin que importen las creencias o el rol que desempeñe el individuo en una organización religiosa" (Salazar Ugarte, 2007). Lo que significa que ninguna entidad religiosa debería ser privilegiada sobre las demás y tampoco ninguna debe discriminarse, se debe, al menos teóricamente, respetar la diversidad y pluralidad de creencias religiosas y al mismo tiempo, respetar a la población agnóstica o atea.

Aquí, la diversidad es comprendida como condición inherente al ser humano, sustentada en las diferencias individuales alrededor de la cultura, la religión, el género, la preferencia sexual, el estrato socioeconómico y los factores de orden intrapsicológicos, interpsicológicos, o ligados a las capacidades funcionales de los seres humanos - necesidades educativas especiales o excepcionales y talentosos (Arnaiz y Haro, 1997).

Reconocer la identidad religiosa minoritaria forma parte de la diversidad, la cual se debería proteger tal y como lo promulga la Constitución Política del país (Congreso de la República de Colombia, 1991). No obstante, los esfuerzos aislados aún son insuficientes para crear una cultura de reconocimiento y respeto por la diferencia; todavía persisten prejuicios y prácticas de discriminación y exclusión por razones de género, religión, características físicas, orientación sexual, entre otros factores, por lo que sería ideal:

Una cultura de la diversidad que no consiste en que las culturas minoritarias se han de someter ('integrar') a las condiciones que le imponga la cultura hegemónica, sino justamente lo contrario: la cultura de la diversidad exige que sea la sociedad la que cambie sus comportamientos y sus actitudes con respecto a los colectivos marginados para que éstos no se vean sometidos a la tiranía de la normalidad (López Melero, 2000, p. 46).

\footnotetext{
4. Acuerdo del 20 de noviembre de 1992 entre la Santa Sede y la República de Colombia, con el cual se introducen modificaciones al Concordato del 12 de julio de 1973.
} 
El reconocimiento de la diversidad obliga a repensar la ERE, elaborar estrategias en las que la igualdad y el reconocimiento dejen de ser una utopía en el entorno del aula, la institución y, por ende, en la sociedad; eliminando situaciones estructurales y las condiciones que permiten la dominación de unas identidades sobre otras, como las minorías religiosas en el sistema educativo marcado por la invisibilización y la injusticia curricular en el que la creencia hegemónica ve atendida sus demandas por encima de las minoritarias (Martínez et al., 2003). Por lo cual, hablar del reconocimiento de la diversidad religiosa en el contexto educativo requiere abordar la educación multicultural, que a su vez implica reconocer que no se coexiste en un mundo homogéneo ni igualitario, sino heterogéneo, plural, habitado por personas con diferentes culturas que no poseen el mismo reconocimiento y poder.

Independiente de la identidad religiosa o civil que profesen los sujetos debe primar el derecho a la educación, ya que, para las escuelas inclusivas, la diversidad se considera una cualidad, en donde la persona puede sentir reconocimiento, seguridad y respeto indistintamente de su identidad. Desde esta óptica, se han reconocido diversos grupos de identidades: grupos raciales, grupos pertenecientes a un determinado género, grupos religiosos, grupos de orientación sexual, grupos de clase socioeconómica, grupos de nacionalidad, etc. Ahora, la religión, como un elemento de la identidad individual y colectiva, impacta la estructura social y las formas de interacción. Se ha sostenido que “[...] el solo hecho de percibir que se pertenece a un grupo de identidad, gatilla el favoritismo y produce una discriminación respecto a los que se ubican fuera de este grupo" (Magendzo, 2007, p. 7).

Adame y Santiago (2009) plantean que la religión, como expresión cultural, determina el accionar social e incide en la identidad colectiva e individual y puede exacerbar las creencias con base en la negación de otros credos generando de esta manera prácticas discriminatorias. Cabe anotar que la religión en la historia, y aún en la actualidad, ha sido causal de guerras y barbaries, no discrimina sexo, edad o condición social, cuando se considera a la religión como parte de una forma de vida específica o, en sí misma, una forma de vida, ofrece identidad a cada una de las distintas maneras de concebir la realidad por parte de sujetos y sociedades; y en general a la religión en diferentes épocas se le atribuye el tipo de pensamientos y acciones morales y éticas de las sociedades.

En lo relativo a las Representaciones Sociales (RS), cabe señalar que, en las últimas décadas, el ser humano ha ido interesándose por comprender a profundidad las diferentes dinámicas sociales y colectivas que se presentan en diferentes contextos y comunidades. Así nace el concepto de RS como categoría de análisis para propiciar el acercamiento a las realidades que emergen entre comunidades, cómo estas cambian y se transforman al pasar de un territorio a otro, oportuna para comprender las subjetividades individuales y sociales. 


\section{Contexto}

La población participante constó de 33 adolescentes: hombres y mujeres con identidades religiosas minoritarias, cuyas edades oscilan entre los 13 y 17 años de edad; miembros de cuatro congregaciones: Iglesia Pentecostal Unida de Colombia (IPUC), Centro de Fe y Esperanza (CFE), Iglesia Cuadrangular (muestra voluntaria); estudiantes que se encontraban cursando bachillerato (grado sexto a once) de colegios públicos y privados (estratos socioeconómicos entre 2 y 4). Se pensó en diferentes grupos religiosos ${ }^{5}$ para identificar voces plurales, diversas identidades que convergen en el entorno educativo.

La Iglesia Pentecostal Unida de Colombia tiene adhesión a una doctrina monoteísta con sus implicaciones Cristocéntricas, ideológicas y práctica del bautismo en el nombre de Jesús; por eso, es considerada como parte de los pentecostales del nombre de Jesucristo o apostólicos. De esta iglesia participaron dos congregaciones ubicadas en diferentes barrios: IPUC La Campiña, Robledo (6 adolescentes), actualmente se congrega un público aproximado de 350 personas (50 de ellas adolescentes); IPUC Santa Cruz, la Rosa (10 adolescentes), con un público asistente en promedio de 200 personas, 35 de ellas adolescentes.

Centro de Fe y Esperanza, Misión Panamericana ubicada en el barrio Robledo con adhesión a la doctrina y bautismo trinitario: Dios (padre) en Jesucristo (hijo) y en el Espíritu Santo, determina ser una iglesia dinámica, fundamentada en principios bíblicos; la asistencia promedio es de 120 personas, participaron 11 adolescentes.

Iglesia Cuadrangular; se llama así porque la doctrina de la Iglesia reconoce cuatro aspectos principales en Jesucristo: salvador, sanador, bautiza con el Espíritu Santo, Rey que viene. Se identifica a sí misma como eminentemente pentecostal en su doctrina y forma de adoración. Se encuentra ubicada en el barrio Córdoba, la asistencia promedio es de 130 personas, participaron 6 adolescentes.

\section{Diseño metodológico}

El paradigma cualitativo fue la ruta metodológica mediante la cual se buscó comprender la perspectiva de los adolescentes acerca de los fenómenos que los rodean, profundizar en sus experiencias, opiniones y significados; es decir, “[...] la forma en que perciben subjetivamente su realidad" (Sampieri et al., 2010, p. 364). Comprender implica profundizar en el texto, su autor, historia de vida, contenidos

5. Acorde con los intereses de la presente investigación, solo se discriminó en la elección de la muestra, congregaciones religiosas no católicas (indeterminadas), que estuvieran dispuestas a participar. 
y significados en el contexto del mundo socio histórico y cultural del que procede; para interpretar, se establece un diálogo con el texto que involucra multiplicidad de sentidos, puntos de vista y concepciones dadas, según el momento, diferente quizá, al momento de producción del texto y al del autor mismo (Arraéz et al., 2006).

Así mismo, la investigación se fundamentó desde un enfoque hermenéutico, disciplina que considera la interpretación de los textos como la comprensión del todo, de la parte y del elemento. Esto implica la interpretación, la detección de nuevas direcciones y la extracción de conclusiones en horizontes de comprensión más amplios. Su función consiste en comprender la conducta de las personas estudiadas, lo cual se logra cuando se interpretan los significados que ellas le dan a su propia conducta y a la conducta de los otros, como también a los objetos que se encuentran en sus ámbitos de convivencia (Martínez Rodriguez, 2011).

Por último, el análisis de caso en los cuatro grupos participantes en la entrevista grupal se realizó siguiendo las pautas del tipo de investigación sugerida, y en razón de los criterios de recurrencia y constancia de postulados en la conversación, buscando así retomar aquellas unidades de significado y profundización, para llegar a la esencia y realidad de lo que piensa cada grupo, procurando rigurosidad en el hallazgo de unidades de análisis, subcategorías y categorías finales.

\section{Discusión general}

En términos de relación entre los cuatro análisis del caso grupal, se encontró como constante que para todos los adolescentes pertenecientes a las diferentes congregaciones, la religión es parte esencial de su identidad, de lo que son, de lo que están construyendo; prueba de esto es que le otorgan sentido a sus vidas de acuerdo a sus creencias religiosas, las cuales determinan representaciones sociales que caracterizan el conocimiento de quiénes son y, por tanto, regulan sus proyectos de vida, cosmovisiones, autoimagen, dotan de sentido su existencia; ya que, sin formación religiosa "la vida no tendría sentido, sería vacía, carecería de valores, orden, leyes".

"La religión disfruta de un notable 'potencial de realidad', es decir, es significativa en términos de los motivos y 'auto interpretaciones' de las personas en su diaria realización social” (Berger, 1999, p. 164). En este sentido, y acorde con los hallazgos y resultados de la presente investigación, se puede afirmar que coherente con la formación religiosa que han adquirido en el hogar, y/o a sus experiencias espirituales, el aspecto religioso es parte vital en la construcción de la identidad de los adolescentes, la cual no es inamovible, no está configurada para siempre; de lo contrario, es variable y se configura mediante las interacciones cotidianas de los individuos con su entorno (Marcús, 2011). 
La identidad se defiende como un valor de la diferencia humana, visible en el contexto social, cultural e histórico, solo cuando se aglomeran narrativas o prácticas en referencia a un grupo que las comparte, similitudes que establecen la noción de minoría. Grupos minoritarios o colectivos que se congregan alrededor de la lengua, la pertenencia étnica, la orientación sexual, el género, la ideología, las prácticas culturales o la estética, para reafirmar y redefinir de manera cotidiana su pluralidad, al validar y cuestionar el concepto de diversidad, en una sociedad cuyas políticas y experiencias locales aseguran el orden hegemónico (Ramírez, 2017, p. 8).

En ese entorno, de construcción identitaria, de diversidad y pluralidad religiosa, tiene lugar la ERE, lo cual suscita la discusión, pues todos esos aspectos que configuran de forma significativa la identidad de los sujetos no son ajenos al contexto educativo, que como pudo observarse dista de una enseñanza plural e intercultural que reconozca las diversas identidades; el problema puede agudizarse en la pregunta expuesta por Rawls: “¿Cómo es posible que exista a través del tiempo una sociedad justa y estable de ciudadanos libres e iguales que, sin embargo, sigan profundamente divididos por doctrinas razonables, religiosas, filosóficas y morales?” (1995, p. 66). El análisis de este interrogante indicaría la forma en que la escuela, y aún más el Estado Colombiano-Laico, debería abordar la cuestión por el lugar de la enseñanza religiosa en la educación pública, en la cual prevalece un sistema de creencias religiosas esencialmente católicas, que como pudo evidenciarse en el estudio realizado, invisibiliza a las demás creencias, además de quienes no profesan ninguna.

Parafraseando a Gómez (2014), favorecer un credo sobre otros en la escuela pública no es compatible con el accionar de una sociedad perteneciente a un Estado pluralista; de tal manera, deberían ser coherentes con esa condición del pluralismo, es decir, con el hecho de que ninguna religión puede pretender ofrecer el punto de vista total y absoluto, la comprensión definitiva y más verdadera de la realidad (Tovar Bernal, 2017). Este tipo de educación contradice el distintivo de imparcialidad de toda institución pública y se opone a su propio marco legislativo y a los tratados suscritos en esta materia:

- Contradice la Constitución Política de 1991: los artículos 1, que establece que “Colombia es un Estado [...] pluralista"; 18 y 19 que garantizan la libertad de cultos, de conciencia y pensamiento, así como el precepto constitucional de que "[t] odas las confesiones religiosas e iglesias son igualmente libres ante la ley" (Congreso de Colombia, 1991).

- Invalida la Ley 133 Estatutaria de Libertad Religiosa y de Cultos de 1994, que en su artículo 2 señala que “[n]inguna Iglesia o Confesión religiosa es ni será oficial o estatal". 
- En el ámbito educativo negaría el artículo 6 del Decreto 4500 de 2006 que establece que: “[n]ingún docente estatal podrá usar su cátedra, de manera sistemática u ocasional, para hacer proselitismo religioso o para impartir una educación religiosa en beneficio de un credo específico"

- En términos de los convenios pactados contradice la Convención Americana sobre derechos Humanos Pacto de San José, que en su artículo 12 proclama la “Libertad de Conciencia y de Religión” (Tovar Bernal, 2017, p. 28).

El respeto por la pluralidad religiosa, por la diferencia, se presenta como una respuesta posible a las dificultades impuestas por la variedad de creencias que tiene lugar en el pluralismo religioso actual; por ende, la escuela como entidad educadora, formadora de ciudadanos competentes para responder y convivir según las demandas sociales, debe ser un escenario central que propicie precisamente esos espacios. Necesario entonces una reconfiguración de la ER, desde el mismo currículo, desde las prácticas, incluso, cómo se comprende la formación integral desde el área específica, "para que haya un verdadero desarrollo integral humano" (Coy, 2010, p. 74). La dimensión espiritual y religiosa tendría que considerarse como fundamental dentro del currículo.

\section{Resultados}

¿Qué significados y experiencias comparten los adolescentes con identidad religiosa minoritaria sobre la enseñanza y el aprendizaje escolar de la religión? En el estudio fue posible encontrar en el discurso de los adolescentes pertenecientes a diferentes minorías religiosas (IPUC, CFE, Cuadrangular) que comparten experiencias alrededor de la enseñanza y el aprendizaje escolar de la religión, así como significados (RS: percepciones, creencias, opiniones, expectativas, actitudes, imaginarios).

En el discurso de los adolescentes se hallan experiencias alrededor de la enseñanza religiosa sin principios sobre multiperspectiva cultural (contenidos, práctica e interacciones). Los adolescentes tienen la percepción de que la enseñanza religiosa no es plural, no reconoce la multiculturalidad en tanto se enseñan contenidos en relación con la adhesión institucional desde la creencia religiosa mayoritaria (sacramentos, eucaristía, historias bíblicas, valores y principios bíblicos) y en algunas ocasiones prácticas religiosas como asistir a misa, rezar, cantar, ponerse la ceniza.

Los jóvenes tienen la percepción de que los docentes del área de religión asumen actitudes de indiferencia ante situaciones que se presentan: discusiones, debates entre estudiantes, conflictos en torno a la religión, mediado por la falta de flexibilidad ideológica y porque responden a la normativa institucional, lo que genera la expectativa por la formación de docentes de religión desde la multiperspectiva religiosa. 
La creencia minoritaria no se modifica por la enseñanza desde la postura hegemónica, en tanto esos contenidos de enseñanza/aprendizaje son de poco interés, no los motiva, no los convoca, la asignatura de religión es la más "fácil y aburrida" (opiniones y percepciones). También, porque tienen muy arraigadas sus creencias religiosas. Así pues aparece la concepción de que el aprendizaje religioso en el entorno educativo no es significativo, aunque en ocasiones pueda complementar las enseñanzas de la congregación, los jóvenes relatan que asisten a la materia por cumplir, por respeto, porque "les toca" puesto que se evalúa y se pierde como las demás.

La enseñanza y aprendizaje de la religión, los cuales generan expectativas y significados en los adolescentes alrededor de los contenidos de la materia: ético, ciudadano, no religioso; permitiendo el reconocimiento de todos y todas, con perspectiva multicultural y donde se implementen metodologías con un enfoque teórico práctico, inclusivas, dialógicas, cooperativas, que permitan el reconocimiento de la identidad y la pluralidad mediante estrategias didácticas que permitan la participación estudiantil como foros y debates, donde se escuche su voz y tengan el derecho a elegir.

La creencia religiosa minoritaria, que como se mencionó está muy arraigada en los adolescentes, regula las concepciones sobre el estilo de vida (sin creencia religiosa, la vida es triste, no tiene sentido, carece de valores), a la vez que promueve imaginarios de los pares frente al joven cristiano en torno a un deber ser. Los adolescentes relatan experiencias en relación a las dinámicas de las interacciones sociales con sus pares, las cuales no se modifican por las creencias religiosas; de lo contrario, hay curiosidad frente a las creencias y prácticas religiosas de los otros, aun cuando ocasionalmente pueden presentarse bullying, estigmatización verbal por medio de apodos, exclusión, críticas, conflictos. Los adolescentes pertenecientes a minorías se autoexcluyen de algunos eventos como actividades y conversaciones, para evitar, según expresan, discusiones.

En Colombia, como pudo observarse en los hallazgos y resultados de la presente investigación, se sigue teniendo retos para atender a una población diversa y plural sin vulnerar sus derechos, como es el caso de las minorías religiosas que se encuentran en el sistema educativo, pero que se les enseña y evalúa desde la religión hegemónica del país.

Las experiencias que narran los adolescentes en los cuatro grupos de caso, frente a la enseñanza y el aprendizaje escolar de la religión, permite visibilizar que aún se dista, en el ámbito local, de reconocer la identidad religiosa minoritaria a la cual están adheridos los estudiantes, como una fuente de información cultural, diversidad, pluralidad, multiperspectiva, sobre la cual asumir los valores humanos universales del respeto hacia la diferencia, la historia de las religiones o la ética de los seres humanos, como eslabones del presente y del futuro, retomados además, por la agenda mundial y el plan de desarrollo educativo nacional. 
La construcción de una auténtica sociedad de derechos igualitarios, implica reconocer la multiperspectiva cultural y religiosa, que en el ámbito colombiano no puede ser eludida, dada la riqueza plural característica del país, la cual se transmuta al entorno educativo, en donde convergen múltiples voces, culturas y pensamientos.

Por tanto, ninguna escuela, dentro de su normativa institucional debe obviar que los estudiantes traen adherida una cultura y presupuestos religiosos desde sus familias, lo cual debe tenerse en cuenta en el proceso de aprendizaje, todas con un pensamiento, una mirada de lo que debe ser la educación, negar esas voces impide acercarnos a la construcción de una auténtica sociedad que respete la pluralidad.

El no reconocimiento de la identidad religiosa, de la pluralidad de sentidos y significados que convergen en el aula de clases en términos de lo religioso, hace de los adolescentes con identidad religiosa minoritaria adscritos a escuelas en donde enseñan y aprenden religión un grupo vulnerable, en tanto aprenden contenidos adheridos a un currículo y a una creencia religiosa de la que difieren desde la obligatoriedad.

También, porque la opción por la adhesión religiosa, asunto que compete a cada individuo desde el derecho a la libertad religiosa, es violentada (consciente o inconscientemente), no se reconoce este derecho. En razón de una creencia se anteponen a derechos fundamentales del niño y adolescente (la libertad de elección) bajo el presupuesto de que niños y adolescentes aún no han desarrollado las capacidades suficientes para tomar una decisión y valorar las consecuencias de adoptar y manifestar alguna religión o creencia. Bajo este razonamiento, niños, niñas y adolescentes han sido excluidos de las decisiones que los involucra respecto a adoptar una creencia religiosa minoritaria o mayoritaria hegemónica o no profesar ningún credo religioso.

Las experiencias y expectativas de los adolescentes en torno al proceso de enseñanza- aprendizaje constituyen un aporte al mejoramiento de las prácticas educativas, puesto que suscitan cambios curriculares y se convierten en posibilidad no solo para reconocerlos como sujetos de derecho activos en la construcción de sociedad, sino también para ahondar en los contenidos y metodologías de enseñanza/aprendizaje desde el protagonismo del sujeto que aprende y se construye; que se interesa por ese aprendizaje, porque no se desconoce su voz, su realidad, sus intereses y problemáticas actuales, a los cuales se les valora sus diversas interpretaciones, cultura, identidad y construcciones en el contexto formativo del aula. 


\section{Conclusiones}

En razón de los hallazgos encontrados se puede concluir que el enfoque de derechos no se operativiza en el entorno educativo, puesto que la diversidad religiosa en ese contexto dista de ser reconocida, no hay equiparación de oportunidades, no se aplica la norma constitucional a los adolescentes con identidad religiosa minoritaria en las escuelas en donde enseñan y aprenden la religión. La pluralidad religiosa es reconocida en el marco legal colombiano; no obstante, a nivel educativo, la diversidad en lo religioso es un asunto por tratar.

Es necesario valorar las expectativas de los adolescentes sobre una educación ética, civil, y perspectiva multicultural, que efectivamente incida en el desarrollo integral y promueva el interés o deseo por aprender; además, considerarlos como sujetos que aprenden, se construyen así mismos desde sus propias interpretaciones, poseedores de bagaje sociocultural, representaciones sociales, intereses. En síntesis, sujetos activos en la construcción de su propio aprendizaje, con voz propia, cuantas veces opacada por la imposición de sus padres, de sus maestros, de sus líderes religiosos, de ellos: sus adultos significantes.

Se reflexiona entonces sobre la voz de los jóvenes, si se tomarán en cuenta como miembros activos de la sociedad, y en este sentido, sus opiniones, sus concepciones, sus apreciaciones frente a la enseñanza, seguramente y lejos de lo que podría pensarse, la pluralidad religiosa no sería motivo de discusión por cómo se afronta dentro del contexto educativo, sino una excusa para explorar la riqueza de la diversidad humana. Los adolescentes deben reconocerse como miembros de derechos activos en la sociedad, lo que implica transformar prácticas y quehaceres institucionales que los incorporen como actores sociales con opinión y posición frente a programas, política, proyectos, “además de hacer de la discusión y la búsqueda del consenso una práctica para la relación con ellos y ellas, en consonancia con su realidad de búsqueda de identidad, libertad, autonomía y verdad" (UNICEF, 2014, p. 13).

Las expectativas que manifiestan los jóvenes realzan el lugar del diálogo interreligioso, los debates, la toma de posición personal, la expresión de opiniones, argumentos, el trabajo con el otro y la colaboración para el aprendizaje; vehiculizando el respeto y el reconocimiento de otras identidades religiosas, bajo el principio del derecho universal, la educación sin ideologías y con contenidos éticos y ciudadanos que garanticen la igualdad, la educación interreligiosa y holística; de donde se deduce que los jóvenes no rechazan la ERE, sino a la forma como se viene abordando.

Los adolescentes participantes en los cuatro grupos de caso, pertenecientes a minorías religiosas no asumen posturas fundamentalistas, sino que reconocen el derecho en términos de libertad e igualdad en el proceso de enseñanza y aprendizaje; a pesar de los dogmas y la formación religiosa preliminar, en sus discursos se muestran respetuosos de las diversas cosmovisiones, ideologías y roles sociales en razón de 
los argumentos, posiciones y conductas diversas y compartidas con sus pares con quienes desean tener relaciones de respeto y de aceptación. Lo que permite concluir que los jóvenes se relacionan con el otro, independiente de sus creencias religiosas (mayoritarias o minoritarias); sus interacciones se regulan por la aceptación y participación en el grupo social y el reconocimiento deseado en cada uno, por parte del otro, características propias del ciclo vital.

Sin embargo, la identidad religiosa minoritaria, las normas, las creencias y los principios que se encuentran arraigados en los adolescentes permean la concepción sobre el mundo, los demás, ellos mismos y sus estilos de vida, denotando sentido de pertenencia con el grupo religioso del cual son adeptos, lo que se pudo ver en las interacciones personales.

En este trabajo, resulta interesante resaltar que los padres aceptan que sus hijos tengan una creencia religiosa minoritaria, aunque difiera de la propia, solo, si notan cambios favorables en sus estilos de vida; de lo que se infiere que, no hay una postura fundamentalista por parte de los padres, sino que lo que les interesa es el bienestar de sus hijos.

Acorde con los hallazgos encontrados, quedan cuestionamientos y vetas de indagación como posibilidad de profundizar en el tema, sobre la formación religiosa en los diversos contextos: familiar, educativo y congregacional, y su incidencia en el desarrollo del pensamiento crítico de los adolescentes, la capacidad para argumentar, preguntar, participar, y no solo ser receptores pasivos, pues como se explicitó en la descripción de los hallazgos, estos se ven a sí mismos sin la capacidad de presentar argumentos sólidos para defender su creencia religiosa ante los demás, lo que les genera inquietudes; al respecto, autores como Acosta Muñoz (2018) plantean que la persona que desarrolla la capacidad crítica entiende mejor su creencia, analiza coherentemente su fe, y depura sus creencias haciéndolas más humana, mirando la realidad individual sin descartar la realidad del otro y del contexto.

Los docentes, aceptando el Proyecto Educativo Institucional, obvian la multiculturalidad que se encuentra en el aula, la postura ideológica de la institución los deja sin opciones para atender la población diversa, lo que facilita el cuestionamiento sobre el rol del docente en la mediación de las situaciones de aula, que no articula la normativa nacional sobre la diversidad religiosa y el derecho a aprender bajo el principio de libertad. El quehacer del docente de religión apuesta por el diálogo interreligioso y el reconocimiento del valor cultural, postulados que se quedan en el discurso (MEN, 2014).

Se cumple con lo previsto en la justificación, en tanto se recoge la voz de los sujetos, sus experiencias, RS en torno a la educación religiosa, por lo cual la investigación resulta innovadora, porque parte de una problemática real y se profundiza en ella, pero además pretende transformar la realidad mediante el diseño de lineamientos para la enseñanza religiosa que propendan por el reconocimiento 
de la identidad religiosa y civil, a través de los hallazgos, del análisis de la voz de los sujetos respecto de sus representaciones sociales.

Es a través de la propuesta de nuevos proyectos, que sean válidos y coherentes, que propongan nuevos contenidos que impliquen a los estudiantes y sean capaces de salirse de lo establecido, de los programas que encorsetan, que estén conectados con la realidad y se asuman por todos los agentes educativos como retos y posibilidades de transformación (Margalef García y Arenas Martija, 2006, p. 16).

Este proyecto, desde una revisión de libros, textos y otros registros le permitieron a la investigación trasegar por la escuela, y sus protagonistas sobre la identidad religiosa de los adolescentes, vehiculizando el respeto y el reconocimiento de otras identidades religiosas, bajo el principio del derecho universal, la educación sin ideologías y con contenidos éticos y ciudadanos que garanticen la igualdad, la educación interreligiosa y holística; de donde se deduce que los jóvenes no rechazan la ERE, sino a la forma como se viene abordando.

\section{Referencias}

Acosta Muñoz, M. (2018). El pensamiento crítico y las creencias religiosas. Sophia,colección de Filosofía de la Educación, 24(1), 209-237.

Adame, M., y Santiago, G. (2009). La religion como una dimensión de la cultura. Nómadas, 1-15.

Arboleda Guerra, C. (2006). Guerra y religión en Colombia. UPB.

Arnaiz, P., y Haro, R. (1997). Educación intercultural y atención a la diversidad. En F. y. Salinas, Semajanzas, diferencias e intervención educativa (pp. 141-148). CSI-CSIF.

Arráez, M., Calles, J., y Moreno de Tovar, L. (2006). La Hermenéutica una actividad interpretativa. Sapiens. Revista Universitaria de Investigación, VII(2), 171-181.

Beltrán, W. (2013). Del monopolio católico a la explosión pentecostal: Pluralización religiosa, secularización y cambio social en Colombia. Universidad Nacional de Colombia. Facultad de Ciencias Humanas. Centro de Estudios Sociales.

Berger, P. (1999). El dosel sagrado: para una teoría sociológica de la religión. Káiros.

Castiblanco, L., y Gómez, L. (2008). La clase de religión en Bogotá: un acercamiento cualitativo a las prácticas y dinámicas de la clase [Tesis de pregrado, no publicada]. F. d. U. Colombia. 
Conferencia Episcopal de Colombia. (2009). Lineamientos de educación religiosa. Básica Secundaria y Educación Media. Conferencia Episcopal para la evangelización de la cultura y la educación. Sección Educación.

Congreso de la República de Colombia. (1991). Constitución Nacional de Colombia. Congreso de la República de Colombia.

Congreso de la República de Colombia. (1994). Ley General de Educación, Ley 115. Ministerio de Educación.

Congreso de la República. (1994). Ley 133 Estatutaria de Libertad Religiosa y de Cultos.

Coy Africano, M. (2010). La educación religiosa escolar en un contexto plural. Reflexiones preliminares. Franciscanum. Revista de las ciencias del espiritu, 52(154), 53-83.

Decreto 4500. (19 de diciembre de 2006). Por el cual se establecen normas sobre la educación religiosa en los establecimientos oficiales y privados de educación preescolar, básica y media. Artículo 6.

Gómez, C. (2014). La religión en la sociedad postsecular: transformación y relocalización de lo religioso en la modernidad tardía. Ediciones Universidad del Rosario.

López Melero, M. (2000). Cortando las amarras de la escuela homogeneizantey segregadora (U. d. Granada, Ed.). Alas para volar, 45-70.

Magendzo, A. (2007). Reflexión en torno a la educación religiosa en una perspectiva de educación pluralista. Revista Internacional Magisterio. Educación y Pedagogía, 14-17.

Marcús, J. (2011). Apuntes sobre el concepto de identidad. Intersticios. Revista Sociológica de Pensamiento Crítico, 107-114.

Margalef García, L., y Arenas Martija, A. (2006). ¿Qué entendemos por innovación educativa? A propósito del desarrollo curricular. Perspectiva Educacional, Formación de profesores, 47, 13-31.

Martínez, J., Sácristán, J., Gutiérrez Pérez, F., Simón, M., y Torres, J. (2003). Ciudadanía, poder y educación. Graó.

Martínez Rodriguez, J. (2011). Métodos de investigación cualitativa. Silogismo. Revista Internacional para el desarrollo educativo, 1-34.

MEN. (s.f.). La enseñanza de la educación religiosa en los establecimientos educativos. Oficina Asesora Jurídica.

MEN. (2012). Propuesta de lineamientos para la formación por Competencias en Educación Súperior. Ministerio de Educación Nacional.

MEN. (2014). Dirección de calidad para la educación, preescolar, básica y media educación religiosa. Ministerio de Educación Nacional. 
Ramírez, P. (2017). Diversidad. Excusa para visibilizar la identidad. En J. Correa (Ed.), Aportes a la comprensión de la vulnerabilidad educativa y social: identidad y equiparación de oportunidades (pp. 7-20). Tecnológico de Antioquia-Institución Universitaria.

Rawls, J. (1995). Liberalismo Político. Fondo de cultura económica: UNAM.

Salazar Ugarte, P. (2007). La laicidad:Antídoto contra la discriminación. Boletín mexicano de derecho comparado.

Sampieri, R., Hernández, C., y Baptista, P. (2010). Metodología de la investigación. McGrawHill.

Tovar Bernal, L. (2017). El lugar de la enseñanza religiosa en la escuela pública en Colombia [Tesis de maestría, no publicada], Colegío Mayor de Nuestra Señora Del Rosario, Escuela de Ciencias Humanas.

UNICEF. (2014). Desarrollo adolescente y derechos humanos. Red de Apoyo por la Justicia y la Paz. 


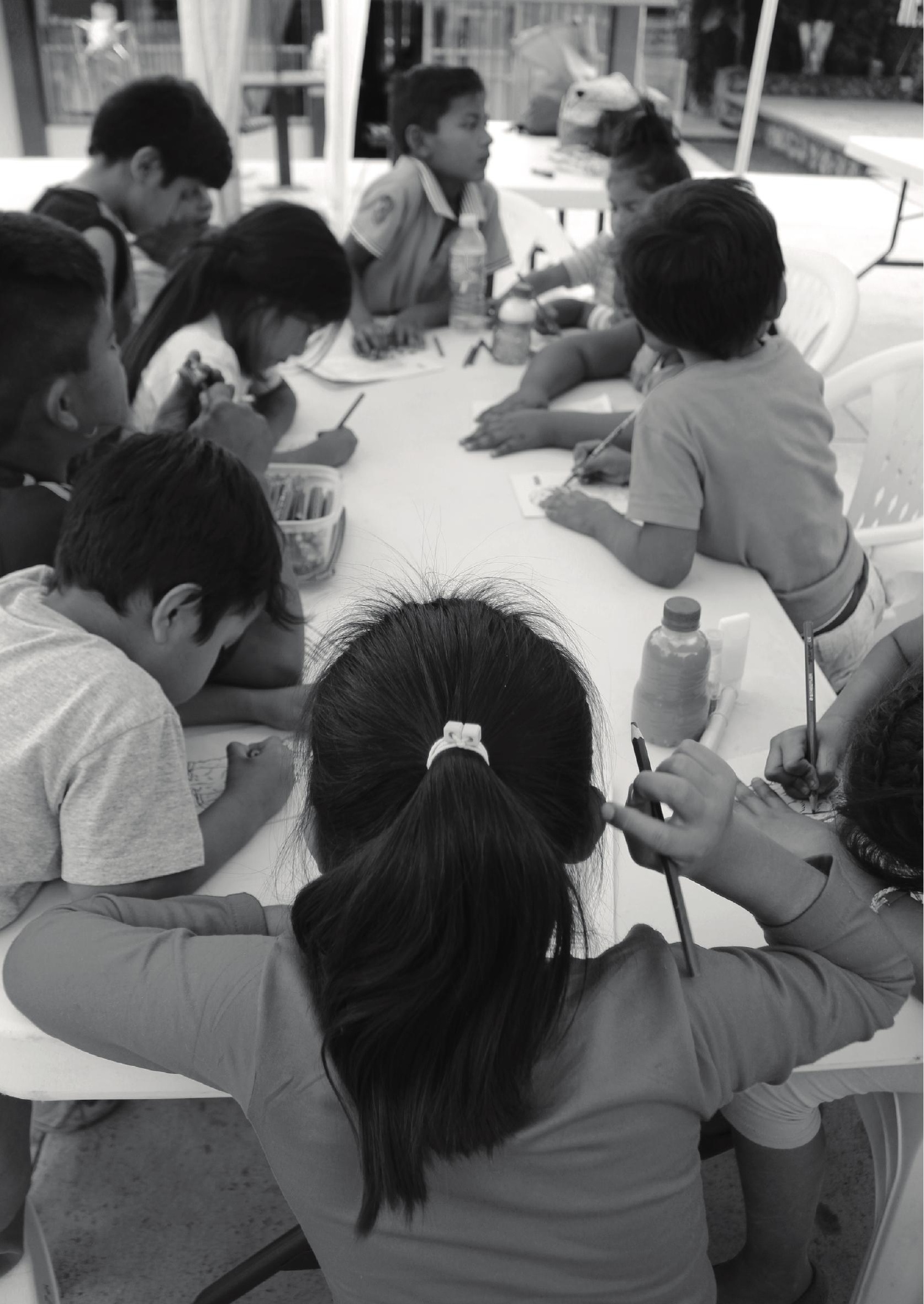

